\title{
From tunnel NMO to layered polymorphs oxides for sodium ion batteries
}

\author{
Michele Nuti ${ }^{1}$. Daniele Spada ${ }^{1}$. Irene Quinzeni ${ }^{1}$. Stefano Capelli ${ }^{2}$. Benedetta Albini ${ }^{3}$. Pietro Galinetto ${ }^{3}$. \\ Marcella Bini ${ }^{1}$ (D)
}

Received: 17 June 2020 / Accepted: 29 September 2020 / Published online: 26 October 2020

(c) The Author(s) 2020 OPEN

\begin{abstract}
The search for highly performing cathode materials for sodium batteries is a fascinating topic. Unfortunately, $\mathrm{Na}_{0.44} \mathrm{MnO}_{2}$ (NMO), the well-known cathode material with good electrochemical performances, suffers from structural degradation due to reduction of $\mathrm{Mn}^{4+}$ to the Jahn-Teller $\mathrm{Mn}^{3+}$ ion, limiting the long-term cyclability. The cation substitution can be a useful way to mitigate the problem, thanks to the possible stabilization of mixtures of different polymorphs. In this paper, $\mathrm{NMO}$ was first substituted with Fe ions, obtaining $\mathrm{Na}_{0.44} \mathrm{Mn}_{0.5} \mathrm{Fe}_{0.5} \mathrm{O}_{2}$, with layered structure, then $\mathrm{Al}$, $\mathrm{Si}$ and $\mathrm{Cu}$ (10\% atom) were substituted on both $\mathrm{Mn}$ and Fe ions. Mixtures of P3 type phases, in different amount depending on dopant, were obtained and quantified by Rietveld refinements, and relationships between chemical composition, polymorph type and morphology were proposed. Cyclic voltammetry showed broad peaks, due to the complex structural transitions consequent to the intercalation/deintercalation of sodium. Charge discharge cycles disclosed the superior performances of Cu doped sample, which also benefits from improved air stability, a well-known issue of layered compounds. Discharge capacity values of about $63 \mathrm{mAh} / \mathrm{g}$ were detected at $1 \mathrm{C}$, and after 50 cycles at C/2, capacities of about $80 \mathrm{mAh} / \mathrm{g}$ are obtained, with a capacity retention of $86 \%$.
\end{abstract}

Keywords $\mathrm{NMO} \cdot \mathrm{XRPD} \cdot$ Raman $\cdot \mathrm{CV} \cdot$ Charge-discharge

\section{Introduction}

Lithium-ion rechargeable batteries (LIBs), the most successful power sources of the modern society for portable electric devices, cannot be employed for the large-scale energy storage due to many drawbacks mainly related to lithium element, such as its low abundance, high cost and nonuniform distribution on the earth crust. There is an urgent need to find an effective alternative.

Very promising candidates for the future replacement of lithium technology seem the Na-ion batteries (NIBs) which can work with the same'rocking chair' storage mechanism of LIBs. Sodium based materials have many different interesting features: they are more abundant, environmental friendly and cheap if compared to lithium analogues [1-3]. Other advantages of sodium are represented by the globally equable distribution of its resources, its suitable redox potential $[-2.71 \mathrm{~V}$ and $-3.04 \mathrm{~V}$ for $\mathrm{Na}$ and $\mathrm{Li}$ versus standard hydrogen electrode (SHE)] and its lightness. In addition, sodium does not alloy with aluminium and therefore Al foil can be used as current collector for both cathode and anode materials, replacing the more

Electronic supplementary material The online version of this article (https://doi.org/10.1007/s42452-020-03607-z) contains supplementary material, which is available to authorized users.

$\triangle$ Marcella Bini, bini@unipv.it | ${ }^{1}$ Chemistry Department, Physical Chemistry Section, University of Pavia, Viale Taramelli 16, 27100 Pavia, Italy. ${ }^{2}$ RSE - Ricerca sul Sistema Energetico, Via R. Rubattino 54, 20134 Milan, Italy. ${ }^{3}$ Physics Department, University of Pavia, Via Bassi 6, 27100 Pavia, Italy. 
expensive and heavier copper, so reducing the costs and increasing the gravimetric energy density of the battery. However, to make these batteries a concrete reality, it was necessary to explore $\mathrm{Na}$ ions intercalation compounds, luckily starting from the multiple knowledge acquired on the analogues LIBs [4]. The most promising positive electrode materials are considered the layered transition metal oxides $\mathrm{Na}_{x} \mathrm{TMO}_{2}(\mathrm{TM}=\mathrm{Ni}, \mathrm{Co}, \mathrm{Mn}, \mathrm{Fe}, \mathrm{Cr}$ and others), mainly owing to their great theoretical capacities. Many other advantages can be listed: superior structural stability, high reversibility for $\mathrm{Na}$-ion extraction/insertion, unlike their $\mathrm{Li}$ analogues, where only $\mathrm{LiCoO}_{2}$ and $\mathrm{LiNiO}_{2}$ show a good ability to intercalate $\mathrm{Li}^{+}$ions, high gravimetric capacity and simplicity of synthesis. The larger size of $\mathrm{Na}^{+}$ (1.02 $\AA$ ) helps to reduce the cation disorder between $\mathrm{Na}^{+}$ ions and the transition metal ions compared to that of $\mathrm{Li}^{+}$ $(0.76 \AA)$, so supporting the intercalation process. However, some drawbacks are represented by the limited cycling life, mainly due to the relatively large size and heavy mass of $\mathrm{Na}^{+}$ions and certain air instability [5, 6]. Different transition metal elements can be chosen and mixed together in various ratios in the layers to produce compounds with tuneable properties for NIBs. In particular, cheap and abundant manganese based cathode materials have been investigated since 1970s [7]. One of the most studied is $\mathrm{Na}_{0.44} \mathrm{MnO}_{2}$ (NMO), with a tunnel opened structure able to allow an easy reversible $\mathrm{Na}^{+}$(de)insertion, that can be favourably obtained from many simple synthesis routes. Its main strengths are the low cost, eco-friendliness and good theoretical capacity (121 $\left.\mathrm{mAh} \mathrm{g}^{-1}\right)$ [8]. Unfortunately, structural degradation and unsatisfactory cycling performance can derive from the Jahn-Teller distortion as a consequence of the reduction of $\mathrm{Mn}^{4+}$ to $\mathrm{Mn}^{3+}$ during the cell functioning. Various approaches have been tried to solve this important limitation: the use of nanotechnology to reduce the particle dimensions, shortening $\mathrm{Na}$-ion diffusion paths and limiting the deformation strain, the increase of electronic conductivity through carbon coating and the metal substitution that, by the decrease of $\mathrm{Mn}^{3+}$ content, can stabilize the crystal structure [9]. For layered compounds the cation substitution can produce different kind of polymorphs, also depending on the experimental synthesis conditions as well as, particularly in the case of multiple and complex substitutions, mixtures of $\mathrm{P}$ and $\mathrm{O}$ phases (following the Delmas notation), [10] so, also for the tunnel structures, a similar behaviour could be expected $[11,12]$. Different elements can be chosen for the substitution on $\mathrm{Mn}$ sites and, in the literature, many kind of chemical compositions are proposed [4]. It was reported, for example, that Fe ions could improve the capacity values as a consequence of the introduction of $\mathrm{Fe}^{3+} / \mathrm{Fe}^{4+}$ active redox couple, differently from the Li analogues [13-15]. $\mathrm{Al}^{3+}$ and $\mathrm{Si}^{4+}$ ions could instead segregate on the particles surface forming a coating layer that could limit the Mn dissolution into the electrolyte, another wellknown issue of $\mathrm{Mn}$ based oxide materials. The doping with $\mathrm{Cu}^{2+}$ ions seems to improve the air stability, so reducing the costs related to the storage and transportation of air sensitive materials $[16,17]$.

In this paper, we synthesized undoped $\mathrm{Na}_{0.44} \mathrm{Mn}_{0.5} \mathrm{Fe}_{0.5} \mathrm{O}_{2}$ and $\mathrm{Na}_{0.44} \mathrm{Mn}_{0.45} \mathrm{Fe}_{0.45} \mathrm{M}_{0.1} \mathrm{O}_{2}$ (M=Al, Si and $\mathrm{Cu}$ ) doped compounds. Al and $\mathrm{Si}$ ions as substituting elements, as far as we know, are employed for the first time in the chemical composition $\mathrm{Na}_{0.44} \mathrm{MO}_{2}$. The samples were characterized by using $\mathrm{X}$-ray powder diffraction with Rietveld structural refinements, to identify and quantify the phases. SEM/EDS were used to examine the particles morphology and the elements homogeneity into the particles. Raman spectroscopy allowed us to verify the octahedral local changes eventually introduced by the dopant ions and by the laser heating. Electrochemical measurements (cyclic voltammetry and charge-discharge cycles) were useful to determine the effect of dopants on cycling performances.

\section{Experimental}

\subsection{Syntheses}

$\mathrm{Na}_{0.44} \mathrm{Mn}_{0.5-(\mathrm{x} / 2)} \mathrm{Fe}_{0.5-(\mathrm{x} / 2)} \mathrm{M}_{\mathrm{x}} \mathrm{O}_{2}(\mathrm{x}=0$ or 0.1$)$ samples were synthesized by means of solid state (undoped and $\mathrm{Cu}$ ) and sol-gel (Al and Si) syntheses.

For a typical solid state synthesis, $\mathrm{Na}_{2} \mathrm{CO}_{3}$ (with $10 \mathrm{wt} \%$ excess), $\mathrm{Fe}_{2} \mathrm{O}_{3}, \mathrm{MnO}$ and $\mathrm{CuO}$ (in case of doping, in the proper amount) were weighted and mixed in a ball milling apparatus (Fritsch, Pulverisette 7). The milling process was performed at $400 \mathrm{rpm}$ for $1 \mathrm{~h}$ in tungsten carbide jars and balls. The mixture was then transferred into an alumina boat and treated in oven in air at $800^{\circ} \mathrm{C}$ for $12 \mathrm{~h}$ (ramps of $5^{\circ} \mathrm{C} / \mathrm{min}$ heating, $10^{\circ} \mathrm{C} / \mathrm{min}$ cooling).

For the sol-gel synthesis, $\mathrm{NaNO}_{3}, \mathrm{Mn}\left(\mathrm{NO}_{3}\right)_{2} 4 \mathrm{H}_{2} \mathrm{O}$, $\mathrm{Fe}\left(\mathrm{NO}_{3}\right)_{3} 9 \mathrm{H}_{2} \mathrm{O}$ with $\mathrm{Al}\left(\mathrm{NO}_{3}\right)_{3} 9 \mathrm{H}_{2} \mathrm{O}$ or TEOS (tetraethyl orthosilicate) and citric acid (2:1 mol with respect to the sum of all the cations) were dissolved in a minimum amount of water and magnetically stirred overnight at about $80^{\circ} \mathrm{C}$. The obtained dry gel was treated in oven at $300{ }^{\circ} \mathrm{C}$ for $3 \mathrm{~h}$ to remove the organic component, then at $750^{\circ} \mathrm{C}$ for $12 \mathrm{~h}$.

All the obtained samples were preserved in a glovebox (MBraun, $\mathrm{O}_{2}<1 \mathrm{ppm}, \mathrm{H}_{2} \mathrm{O}<1 \mathrm{ppm}$ ) to avoid the contact with moisture.

In the following, $\mathrm{Na}_{0.44} \mathrm{M} \mathrm{n}_{0.5} \mathrm{Fe}_{0.5} \mathrm{O}_{2}$, $\mathrm{Na}_{0.44} \mathrm{Mn}_{0.45} \mathrm{Fe}_{0.45} \mathrm{Al}_{0.1} \mathrm{O}_{2}, \mathrm{Na}_{0.44} \mathrm{Mn}_{0.45} \mathrm{Fe}_{0.45} \mathrm{Si}_{0.1} \mathrm{O}_{2}$ and $\mathrm{Na}_{0.44} \mathrm{Mn}_{0.45} \mathrm{Fe}_{0.45} \mathrm{Cu}_{0.1} \mathrm{O}_{2}$ will be named NMFO, NMFO-Al, NMFO-Si and NMFO-Cu, respectively. 


\subsection{Instruments}

X-ray powder diffraction (XRPD) measurements were collected on a Bruker D5005 diffractometer with CuKa radiation $(40 \mathrm{kV}, 40 \mathrm{~mA})$, graphite monochromator and scintillation detector. The angular range was $10-70^{\circ}$, the step size $0.03^{\circ}$ and counting time $2 \mathrm{~s} / \mathrm{step}$ and use was made of a silicon sample holder with low background. TOPAS 3.0 software [18] was used to perform the Rietveld structural and profile refinement based on the known $\mathrm{P}$ and $\mathrm{O}$ crystal structure models for layered materials $[1,10]$. The background coefficients, scale factor, zero or displacement error, lattice parameters, crystallite sizes, isotropic thermal factors and atomic positions were varied during the refinement. The Na occupancies were varied with suitable constraints, while those of the other sites were maintained fixed to stoichiometric values. XRPD patterns were also collected after storage in air for one month, to verify the materials stability in air.

A Tescan Mira3 Scanning Electron Microscope (SEM) was used for the morphological study on gold sputtered samples. Energy-Dispersive X-ray Spectroscopy (EDS) analysis was also performed with the same instrument on as it is powder samples.

Room temperature micro-Raman spectra were performed by means of a Labram Dilor spectrometer equipped with an Olympus microscope HS BX40. The Raman signals were excited by the $632.8 \mathrm{~nm}$ red light from a $25 \mathrm{~mW}$ He-Ne laser. A cooled CCD detector with 2048 pixels was used as a detector determining also a spectral resolution at about $1 \mathrm{~cm}^{-1}$. The reported spectra were obtained with typical integration times of about $60 \mathrm{~s}$ and averaged over 3 runs. The spatial resolution of sampling was around $2 \mu \mathrm{m}$ diameter due to the focussing of the laser by a $50 \mathrm{X}$ objective.

The slurries for the electrochemical measurements were prepared by mixing the active materials (NMFO or doped analogues) with carbon Super C65 and Polyvinylidene fluoride (PVdF) binder in a weight ratio of 80:10:10 in $\mathrm{N}$-methyl-2-pyrrolidone (NMP, Aldrich, anhydrous). Carbon and PVdF were treated in oven overnight at about $70^{\circ} \mathrm{C}$ to remove the eventual absorbed moisture. The dispersions were magnetically stirred for about one hour, afterwards, coated on an aluminium foil by using a homemade doctor blade, maintained overnight at room temperature in a vacuum oven, then dried in the same apparatus at $100^{\circ} \mathrm{C}$ for $1 \mathrm{~h}$ and hot pressed with 200 psi at $95^{\circ} \mathrm{C}$ for $5 \mathrm{~min}$. The electrodes were cut in form of discs $(1 \mathrm{~cm}$ of diameter), with a mass loading of about $2 \mathrm{mg} / \mathrm{cm}^{2}$. Swagelok cells were assembled in dry box under argon atmosphere (MBraun, $\mathrm{O}_{2}<1 \mathrm{ppm}, \mathrm{H}_{2} \mathrm{O}<1 \mathrm{ppm}$ ) with the prepared slurries as working electrode, $\mathrm{Na}$ metal as the reference and counter electrode and a Whatman GF/A disc as the separator. The electrolyte was $1 \mathrm{M} \mathrm{NaPF}_{6}$ in propylene carbonate (PC).

Cyclic voltammetry (CV) was performed at a scan rate of $0.1 \mathrm{mV} / \mathrm{s}$ for six cycles in the potential range $1.5-4.8 \mathrm{~V}$ by using an Autolab PGSTAT30 (Eco Chemie). For galvanostatic charge-discharge tests, the Swagelok cells were cycled on a Neware battery tester in the $1.5-4.8 \mathrm{~V}$ potential range for 10 cycles at $C$-rates between $C / 2$ and $5 C$.

\section{Results}

\subsection{XRPD}

The XRPD patterns of all the synthesized samples are compared in Fig. 1a-d curves: some similarities are evident, in particular the main peak at about $16^{\circ}$ is common to all the patterns, as well as those at about $37^{\circ}$ and $45^{\circ}$. Differences can be anyway observed, particularly for the undoped and NMFO-Cu samples, suggesting that the introduction of a small amount of dopant is able to introduce pronounced structural changes. It seems that $\mathrm{Si}$ and $\mathrm{Al}$ ions, due to their patterns' similarity, cause a similar structure stabilization,
Fig. 1 XRPD patterns of all the synthesized samples before (a-d) and after ( $\left.\mathbf{a}^{\prime}-\mathbf{d}^{\prime}\right)$ air exposure. The letters indicate $\mathbf{a}$ NMFO, b NMFO-Al, c NMFO-Si and (d) NMFO-Cu samples

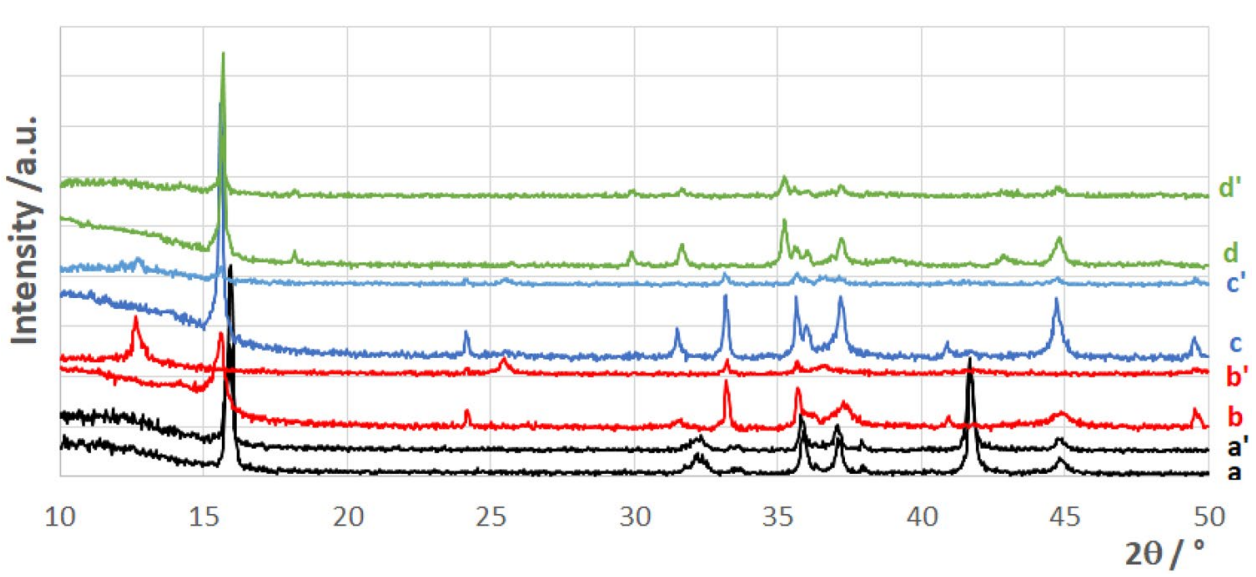

SN Applied Sciences A SPRINGER NATURE journa 
while undoped and $\mathrm{Cu}$ doped have different patterns. In all the cases, however, a complex phases' stabilization can be supposed. This behaviour was expected $[19,20]$, and also desired: in fact, for similar cathode materials, small deviations from sodium stoichiometry as well as the cation substitution can produce mixtures of phases, which can be beneficial for the electrochemical application $[1,3]$.

In order to precisely determine the kind of structures as well as their amount (plus, in some cases, traces of impurity phases), Rietveld structural refinements were performed on all the samples on the basis of the $\mathrm{P}$ and $\mathrm{O}$ structural models reported in the literature $[10,14,19]$. It is wellknown that the most common $\mathrm{Na}_{x} \mathrm{MeO}_{2}$ layered structures are built up of sheets of edge-sharing $\mathrm{MeO}_{6}$ octahedra, and polymorphism appears when the sheets are stacked with different orientations along the $c$-axis direction. The $\mathrm{Na} / \mathrm{Me}$ ratio, as well as the chosen synthesis conditions, could drive the formation of a peculiar structure or mixtures of them. P-type phases are in general stabilized for $x \leq 0.6-0.7$, while O-type for $x \approx 1$ [1]. In particular, P2, considered the most stable phase, has the lowest energy in the region $1 / 3<x<2 / 3$, while after removing all $\mathrm{Na}$-ions $(x=0), \mathrm{O} 2$ is instead the most stable. $\mathrm{O} 3$ phase converts, during cycling, into $\mathrm{P} 3$, which can be however also synthesized by conventional solid-state reaction $[3,21]$.

In Fig. 2 the comparisons between the experimental pattern (blue) and the calculated one (red) on the basis of the Rietveld method are reported for all the samples, together with the difference curve (grey) and the bars of the expected reflections positions for all the phases. In Tab. 1 the main structural parameters and the goodness of fit (GoF) are shown. We should take into account that multiphase refinements are common in the literature, but the actual cases are complex, because the involved polymorphs are structurally similar, with extended peaks overlapping, making the quantitative analysis a challenge. The graphical comparisons are good, suggesting reliable structural refinements, as demonstrated by both the difference curves, as well as by the GoF values, the most reliable agreement index, all close to 1 , the reference value. The samples are constituted by a mixture of phases, mainly of the P-type, i.e. with $\mathrm{Na}$ ions in prismatic coordination [10]. This is expected, due to the Na amount of 0.44 , favouring such kind of coordination. Only for NMFO the $\mathrm{O} 3$ phase is detected, as demonstrated by the intense peak at about $42^{\circ}$, a marker for this phase. In Tab. 1 the Na amount of the different polymorphs is also reported, as determined from the $\mathrm{Na}$ occupancy variations during the refinements. It is evident that almost all the P-type phases contain a sodium amount of about 0.4 , while the $\mathrm{O} 3$ phase is more sodiated, as expected on the base of literature [1].

From Table 1 it can be seen that the crystallite sizes of the phases in a sample are similar, particularly for NMFO$\mathrm{Cu}$ and NMFO-Al, suggesting a similar structural ordering
Fig. 2 Comparison between the experimental (blue) and the calculated (red) patterns on the base of the Rietveld refinement for all the samples. The difference curve (grey) and the bars of the expected peak positions of all the coexisting phases are reported in the bottom. The stars indicate the $\mathrm{Fe}_{3} \mathrm{O}_{4}$ reflections

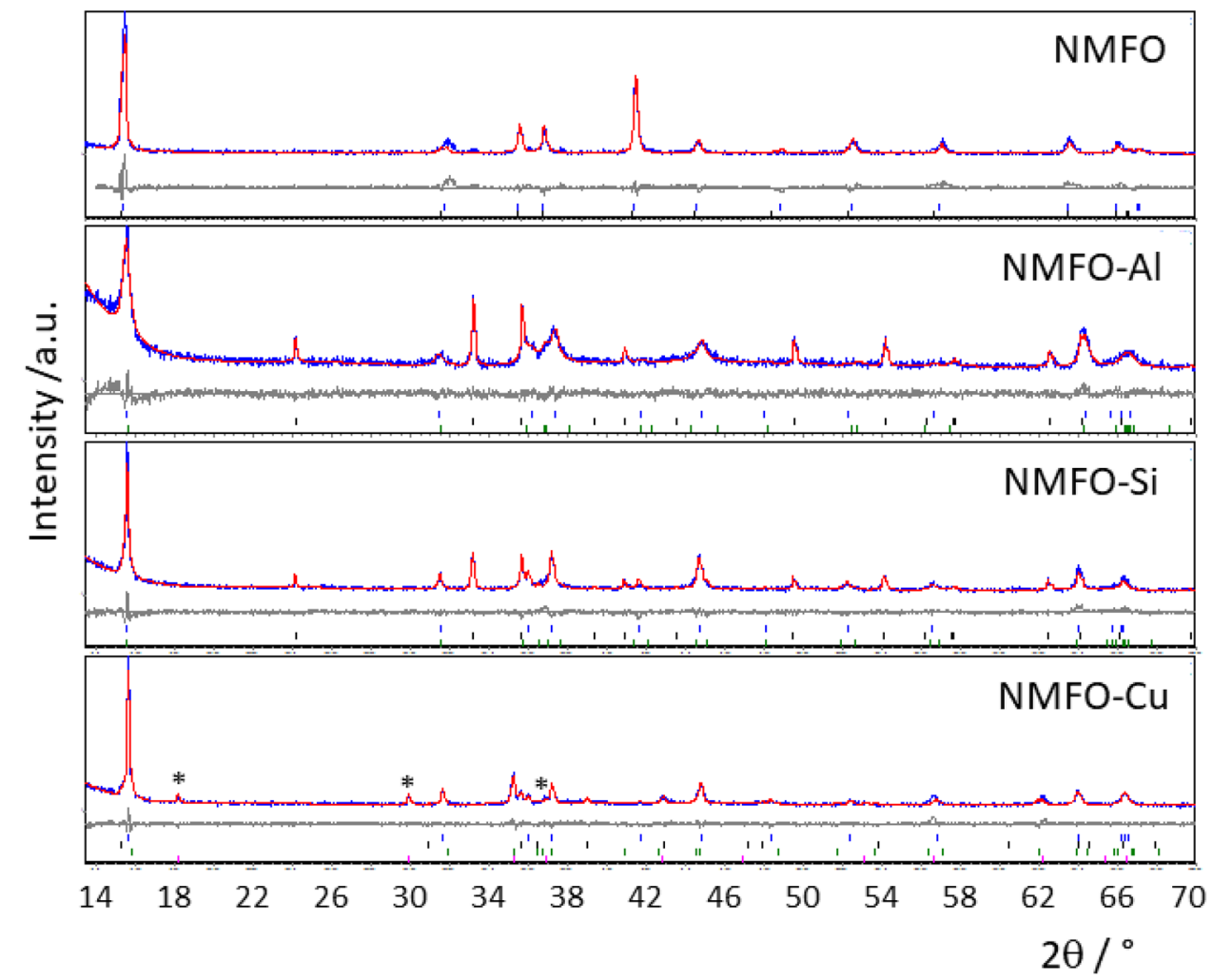


degree of the coexisting layered polymorphs. Values between 50 and $80 \mathrm{~nm}$ are determined, apart from NMFO$\mathrm{Al}$, which has halved values and, in general, low crystallinity. The lattice parameters of the $\mathrm{P} 3$ phase are practically the same in all the samples, apart again from NMFO-Al in which the $c$ - axis is the longest one.

The absence of impurity phases containing the dopant ions suggests that the substituents are hosted in the layered structures, but finding their right location is a difficult task, also due to their small amount. Notwithstanding the $\mathrm{Al}$, Si and Cu ions preference towards tetrahedral or planar coordination, small amount of them could easily locate also on octahedral sites, as also found in other papers for similar layered materials $[16,17]$.

Layered compounds are known to possess low stability when exposed to moisture, so it is mandatory to stock them in dry box. To verify if the dopant ions improved the air stability, the samples were maintained one month in air after their preparation, then the XRPD patterns were collected (Fig. 1a'-d'). It is evident that in almost all the cases significant differences appear, suggesting that degradation occurred. For undoped NMFO, a good stability is proved, even if the formation of the broad band centred at about $12^{\circ}$ could suggest a tendency towards degradation. The peak at about $13^{\circ}$, typical of "hydrated phases" [3, 22], is clearly evident in NMFO-Si and NMFO-Al samples, and in this last one the main peak at about $16^{\circ}$ is completely absent. It seems that these dopant ions could increase the degradation rate of the samples, maybe due to a possible formation of layered polymorphs with slightly different dopant content that differently distribute on surface and bulk of the samples. So, if higher substituent amount is present on the surface, due to their easy tendency of reaction towards moisture, the degradation could be more rapid. For NMFO-Cu the patterns are practically coincident, suggesting the high stability of the sample, due to the favourable effect of $\mathrm{Cu}$ ions $[17,23]$.

\subsection{SEM-EDS}

SEM analysis was performed on all the samples to verify the eventual doping effect on the particles' morphology. In Fig. 3 the micrographs at two different magnifications are reported. A high agglomeration level is evident: all the samples are constituted by large particles, in turn made of smaller ones. NMFO shows flat flake-like grains, partly visible also in NMFO-Al. For this last one, some sticks are also present, together with aggregates of spherical particles, as well as for NMFO-Cu, that shows most spherical particles. The external morphology of particles is clearly dependent on different parameters, such as temperature, time, chemical composition and structure but, in our experimental synthesis conditions, the markedly different aspect of NMFO sample could suggest that the peculiar flake-like morphology may belong to $\mathrm{O} 3$ type phase, the prevailing in NMFO sample, as also found in the literature for another $\mathrm{O} 3$ phase [24]. For the other samples, containing only P-type phases no particular structure-morphologies relationships can be found.

To verify the dopant amount and its distribution into the powders, EDS analysis was performed (Fig. 4 for NMFO and NMFO-Cu and Fig. S1 and S2 for NMFO-Al and NMFO$\mathrm{Si}$, respectively). The spectra were collected in different points of the samples: for simplicity, when similar compositions were detected, only one example will be shown. The spectra show that all the elements $(\mathrm{Na}, \mathrm{Mn}, \mathrm{Fe}, \mathrm{O}$ and dopants) are present, in general in the stoichiometric ratio, suggesting also that stoichiometric sodium was preserved in the sample. Undoped NMFO has the expected chemical composition, as well as NMFO-Al sample, in which the determined stoichiometry is in great agreement with the expected one (Figs. 4 and S1). For NMFO-Si, silicon loss occurred: its amount is halved with respect to the stoichiometric one, suggesting a possible silicon leak during the synthesis, probably due to the affinity of silicon towards the glass beaker used during the sol-gel synthesis. The NMFO-Cu sample apparently presents some inhomogeneity: at least two different regions were determined, one with a high $\mathrm{Na}$ amount and stoichiometric $\mathrm{Cu}$ and the other with lower $\mathrm{Cu}$ amount and stoichiometric $\mathrm{Na}$.

The dopants are not present as separated phases (such as oxides), as evident from the similarity of composition from different sample points, as well as from XRPD data, so suggesting their incorporation into the layered structures.

\subsection{Micro-Raman}

The Raman spectra can be analysed in comparison with the Raman signal from the NMO parent compound. Its spectrum is dominated by two bands, centred at $550-600 \mathrm{~cm}^{-1}$ and $620-650 \mathrm{~cm}^{-1}$, due to the transition metals located into octahedral sites. The first one, usually less intense, is attributed to $\mathrm{Mn}-\mathrm{O}$ vibrations in the basal plane of $\mathrm{MnO}_{6}$, the second one to $\mathrm{Mn}-\mathrm{O}$ stretching modes. Weaker signals, detected at lower energies, are mainly due to bending modes of $\mathrm{Mn}-\mathrm{O}$ bonds.

In the NMFO spectrum (Fig. 5) a broad signal is observed at about $600 \mathrm{~cm}^{-1}$ likely due to the overlapping of the stretching modes inside the octahedral units, but involving different cations ( $\mathrm{Mn}$ and $\mathrm{Fe}$ ), present in equal amount into $\mathrm{Na}_{0.44} \mathrm{Mn}_{0.5} \mathrm{Fe}_{0.5} \mathrm{O}_{2}$. A small peak at about $1100 \mathrm{~cm}^{-1}$ can be due to traces of $\mathrm{Na}_{2} \mathrm{CO}_{3}$. After the irradiation of the powder with the laser at the maximum power, the spectrum has low intensities and is dominated by the only peak at about $630 \mathrm{~cm}^{-1}$. The contribution of the vibrations into the basal plane is practically vanished, suggesting the 
Fig. 3 SEM images at two different magnification ( 5 and 20 $\mathrm{kX}$ ) of all the prepared samples

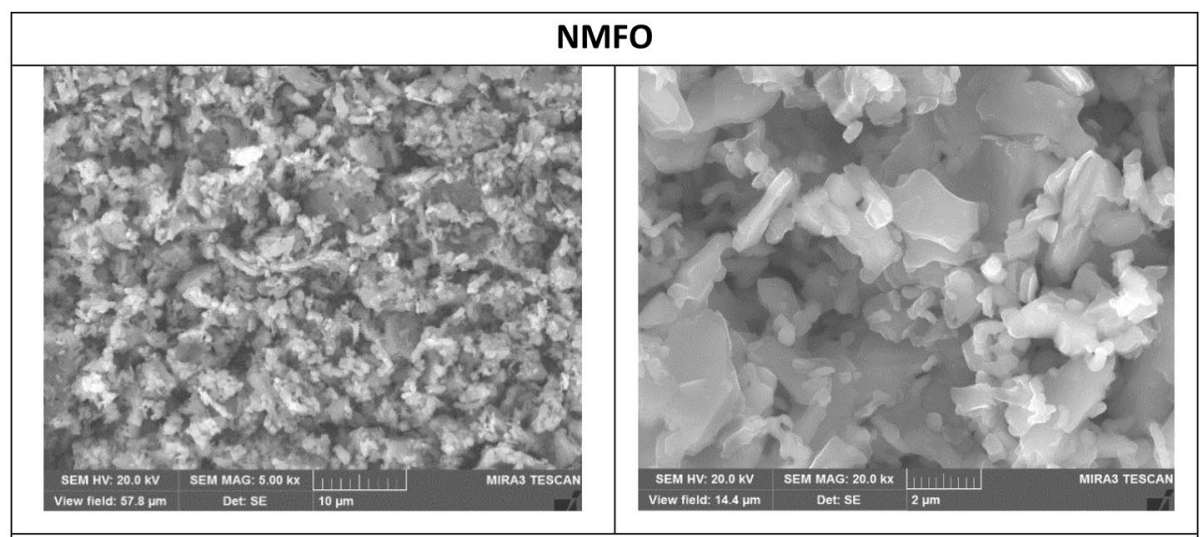

NMFO-Al
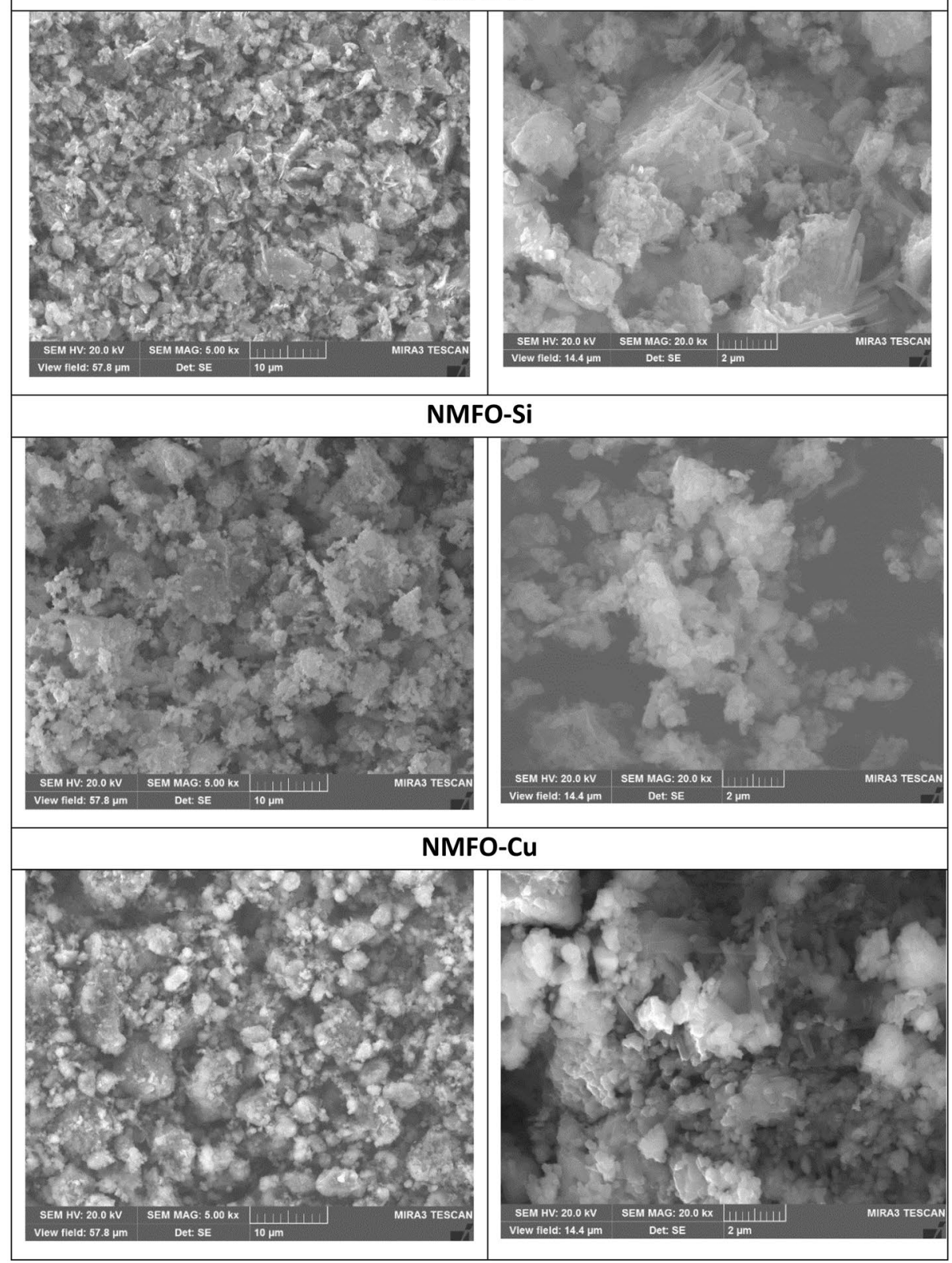


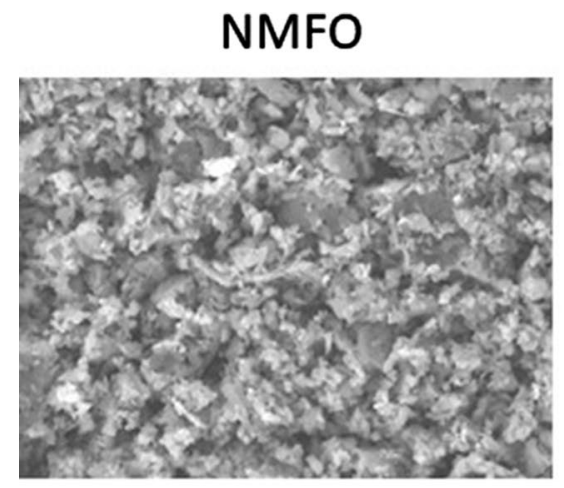

\section{Cps/eV}

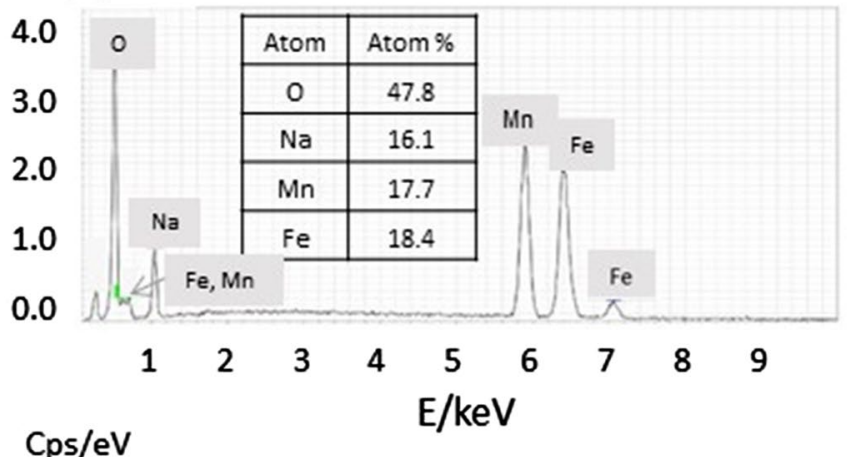

NMFO-Cu

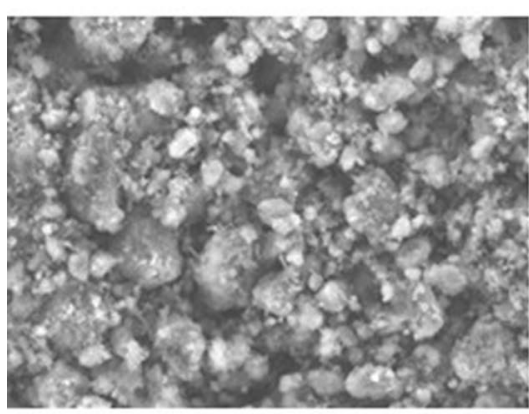

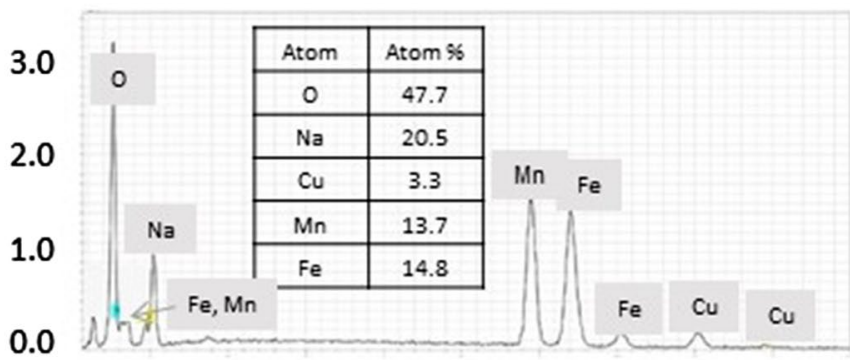

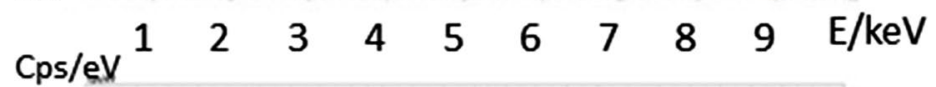

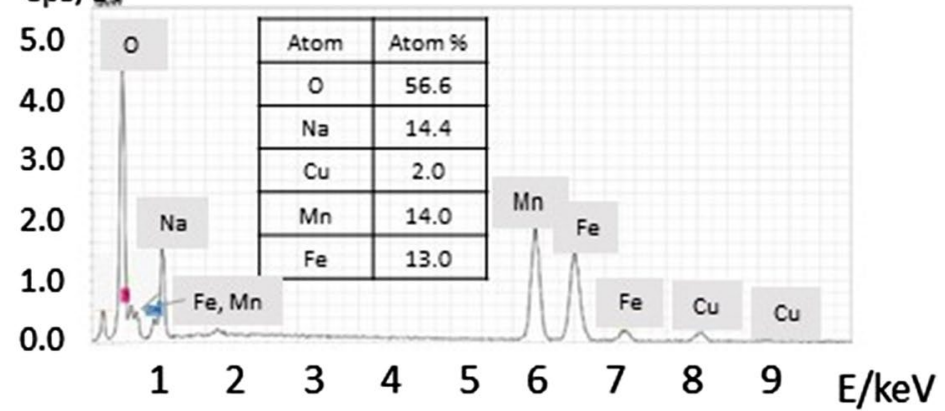

Fig. 4 SEM images, EDS spectra and tables with the atomic composition for the NMFO and NMFO-Cu samples

increase of disorder or at least an increased lattice distortion. The carbonate band is also absent, due to its possible decomposition because the local heating.

The NMFO-Al and NMFO-Si Raman spectra are very similar (Fig. 5). The main peaks are the same identified in the NMFO sample. The small peaks at low Raman shifts values are due to traces of hematite, as also detected by XRPD (Table 1). Also in this case the laser heating causes a decrease of the whole Raman yield and a red shift can be observed. Another important observation is related to the low number of bands, suggesting that the application of the maximum power of laser could help to complete the chemical reaction. All the peaks in the Raman spectrum of NMFO-Cu sample can be attributed to the layered oxide structure, without evidence of secondary phases. The laser at the maximum power produces the same effects as for the other samples.
By closely inspecting the band at about $600 \mathrm{~cm}^{-1}$, one can notice that a different relative ratio of the two components is observed. Indeed, for the doped samples, the intensity of the Raman band peaked just below $600 \mathrm{~cm}^{-1}$, usually attributed to the vibrations in the octahedral basal plane, increases with respect to the intensity of the higher energy component. According to ref.19, the relative ratio of these two components can be considered as a marker of the local lattice distortions around $\mathrm{Mn}$ and $\mathrm{Fe}$ ions. In the undoped samples this ratio is low, being the $A_{1 \mathrm{~g}}$ mode at $635 \mathrm{~cm}^{-1}$ markedly higher. This indicates that a severe distortion characterizes the octahedra in the pure compound. On the contrary, the effect of doping seems to cause a reduction in the distortion and a consequent relative increase in the intensity just below $600 \mathrm{~cm}^{-1}$. This evidence is clearly related to the different kind of phases involved in the 

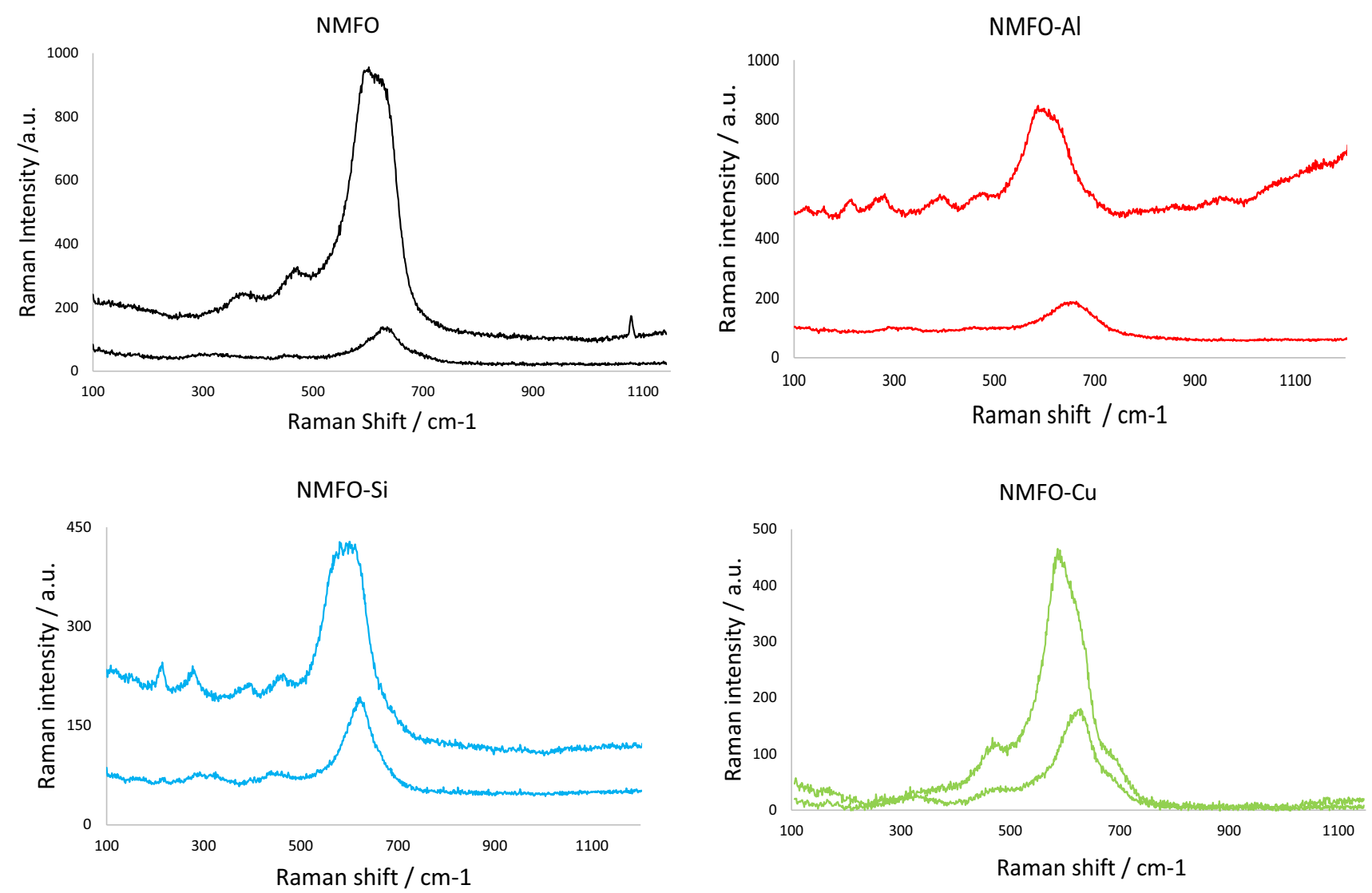

Fig. 5 Raman Spectra of the analysed samples before (top) and after (bottom) irradiation with the laser at the maximum power

samples: NMFO is mainly constituted by the $\mathrm{O} 3$ polymorph, while the doped samples by mixtures of $P$ phases (Tab. 1). In the undoped sample, $\mathrm{O} 3$ phase seems to have a pronounced Jahn-Teller distortion that produces an asymmetry of the modes around $600 \mathrm{~cm}^{-1}$, in particular that at $635 \mathrm{~cm}^{-1}$ is very high, more than in the P-type phases.

\subsection{Cyclic voltammetry}

Cyclic voltammetry was used to verify the electrochemical processes that occur in the samples and to possibly attribute them to specific redox couples. In Fig. 6A-D the curves of the six CV cycles of all the samples are shown. All the curves show broad peaks, with two main couples of peaks well evident in all the samples. Notwithstanding the difficulty to precisely assign the phenomena, it can be stated that the peak at about $3 \mathrm{~V}$ can be due to the $\mathrm{Mn}^{3+} / \mathrm{Mn}^{4+}$ redox couple, while the one at about $4.2 \mathrm{~V}$ to $\mathrm{Fe}^{3+} / \mathrm{Fe}^{4+}[13,14]$. The large broadening can suggest that the electrochemical phenomena occurs in a wide potential window, due to the coexistence of structurally different phases in the samples, as demonstrated by XRPD (Table 1), which causes a distribution of the potential values corresponding to the same phenomenon. This effect is well known in the literature [24]. Only for NMFO-Cu sample, the peak at higher potential is more defined, clearly showing the discussed overlapping of phenomena, attributed to different phases. Taking into account that the sharpness of a peak is an index of the invariance in the free energy associated with the electrochemical reaction, and secondly, that most of the aforementioned free energy is given by the site energy, we can assume that the structure of NMFO-Cu upon cycling is less distorted than the other samples. The NMFO-Al sample has a very low intensity: we can hypothesize that, if some Al inhomogeneity onto the layered polymorphs was present and the Al richer reside on the particle surface, a sort of "coating" could be obtained reducing the global signal intensity [25]. Passing from the first to the sixth cycle the peak intensities tend to decrease, particularly for the $\mathrm{Fe}^{3+} / \mathrm{Fe}^{4+}$ redox couple, but also shifts towards lower or higher potential values can be detected. These effects are related to the structural changes occurring during cycling: in particular, for the anodic scan, the decrease in the electrochemical potential means an increase in the energy site. The increase in the site energy can negatively affect the long-term 
Table 1 Lattice parameters, weight amount, crystallite sizes and $\mathrm{Na}$ amount in $\mathrm{Na}_{\mathrm{x}} \mathrm{Mn}_{0.5} \mathrm{Fe}_{0.5} \mathrm{O}_{2}$ and $\mathrm{Na}_{\mathrm{x}} \mathrm{Mn}_{0.45} \mathrm{Fe}_{0.45} \mathrm{M}_{0.1} \mathrm{O}_{2}$ obtained from Rietveld refinements for all the samples, together with the goodness of fit ${ }^{*}$ secondary phase, not relevant to the discussion)

\begin{tabular}{|c|c|c|c|c|c|}
\hline & $\begin{array}{l}\text { Phase amount/ } \\
\mathrm{wt} \%\end{array}$ & Na amount & Lattice parameters/Å & Cry size/nm & GoF \\
\hline \multicolumn{6}{|l|}{ NMFO } \\
\hline $\mathrm{O} 3$ & 69 & 0.55 & $\begin{array}{l}2.9270(4) \\
16.7255(39)\end{array}$ & $72(4)$ & 1.5 \\
\hline P3 & 31 & 0.20 & $\begin{array}{l}2.9269(5) \\
16.8524(56)\end{array}$ & $50(3)$ & \\
\hline \multicolumn{6}{|l|}{ NMFO-Al } \\
\hline P3 & 21 & 0.35 & $\begin{array}{l}2.8944(6) \\
17.0709(65)\end{array}$ & $22(1)$ & 1.09 \\
\hline$P^{\prime} 3$ & 78 & 0.4 & $\begin{array}{l}5.0646(17) \\
2.8159(10) \\
5.8922(61) \\
105.98(8)\end{array}$ & $20(1)$ & \\
\hline \multicolumn{6}{|l|}{ NMFO-Si } \\
\hline P3 & 82 & 0.4 & $\begin{array}{l}2.9089(2) \\
17.0253(28)\end{array}$ & $50(1)$ & 1.19 \\
\hline$P^{\prime} 3$ & 15 & 0.4 & $\begin{array}{l}5.0754(18) \\
2.8500(11) \\
5.9277(21) \\
106.76(3)\end{array}$ & $80(1)$ & \\
\hline $\begin{array}{l}\mathrm{Fe}_{2} \mathrm{O}_{3}{ }^{*} \\
\mathrm{NMFO}-\mathrm{Cu}\end{array}$ & 3 & & - & - & \\
\hline P3 & 32 & 0.4 & $\begin{array}{l}2.9083(2) \\
16.9341(22)\end{array}$ & $67(2)$ & 1.23 \\
\hline$P^{\prime} 3$ & 59 & 0.45 & $\begin{array}{l}5.0022(14) \\
2.9923(4) \\
5.7968(53) \\
105.07(5)\end{array}$ & $60(4)$ & \\
\hline P2 & 6 & 0.4 & $\begin{array}{l}2.9067(5) \\
11.5519(70)\end{array}$ & $70(3)$ & \\
\hline $\mathrm{Fe}_{3} \mathrm{O}_{4}^{*}$ & 3 & & - & - & \\
\hline
\end{tabular}

stability. It seems that the intensity decrease during cycling can be limited by the dopant introduction into the crystal lattice, in particular for Cu doping, that has the better reversibility. In Fig. $6 \mathrm{E}$ the comparison of the normalized third cycles of all the samples is shown (as mentioned, the current density would be much lower for NMFO and NMFO-Al, hindering an efficient comparison). Both the $\mathrm{Si}$ - and $\mathrm{Cu}$ - samples show higher peak resolution, hence sharper peaks. As already mentioned, this can be an index of higher structural stability. Another indication of better performance is given by the lower and flatter background current at the high- and low-end of the voltammogram, which suggests smaller cell resistance manifested as a lower ohmic drop. The better performance of these samples can also be explained with an improved electron conductivity, which can be foreseen in the lower ohmic drop. The little differences between the peak potentials can be attributed to the influence of the dopant ions, slightly altering the $\mathrm{M}-\mathrm{O}$ bond energies and affecting the site energy.

\subsection{Charge-discharge cycles}

To evaluate the influence of dopants on the electrochemical performance of the materials, charge-discharge cycles were performed for all the samples at different C-rates (Fig. 7). The theoretical capacity of the undoped $\mathrm{Na}_{0.44} \mathrm{Mn}_{0.5} \mathrm{Fe}_{0.5} \mathrm{O}_{2}$ is $121 \mathrm{mAh} / \mathrm{g}$, practically unchanged when small dopant amount are introduced. It is well evident that at the lowest $C$ rate $(C / 10)$ the best performance is shown by NMFO-Cu, followed by NMFO-Si with discharge capacities very close to the theoretical one. NMFO-Al and NMFO show in general much lower capacity values, even at the lowest $\mathrm{C}$-rates. For the Al doping the charge-discharge measurements reinforce the hypotheses made about CV curves: it is very likely that Al ions segregate on particle surface forming a coating layer inhibiting $\mathrm{Na}$ intercalation/deintercalation, hence worsening 

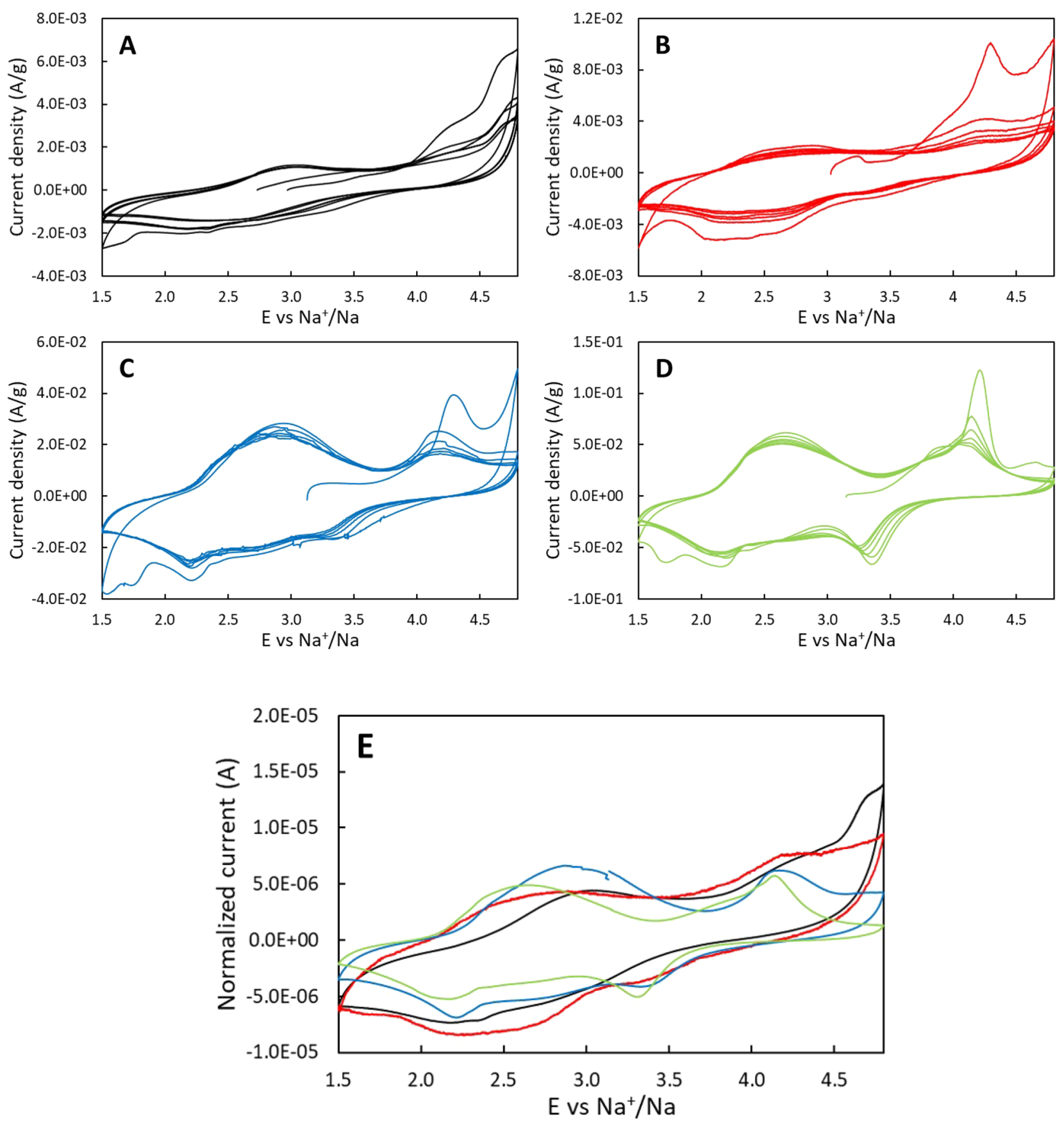

Fig. 6 CV curves of the six cycles of A NMFO, B NMFO-Al, C NMFO-Si and D NMFO-Cu samples in the potential range 1.5-4.8 V at 0.1 mV/s; E comparison between the third cycle of all the samples

its performance. The better performance is shown at all the C-rates by NMFO-Cu sample, that even at $2 \mathrm{C}$ has a discharge capacity of about $45 \mathrm{mAh} / \mathrm{g}$. At the highest $C$ values (5C) all the doped samples have similar capacities. After cycling, when 10 cycles are again performed at $\mathrm{C} / 2$ all the samples can recover the initial capacities, suggesting reversible structural changes and a stable and strong lattice framework. The capacity loss during cycling is a phenomenon related to the reactions between the manganese-rich cathode and the electrolyte, promoting the dissolution of manganese ions into the electrolyte, followed by their migration and deposition at the anode, which results in a significant capacity loss.

A prolonged cycling was performed for the most promising samples: NMFO-Cu and NMFO-Si were cycled for 50 cycles at C/2 (Fig. 7). The capacity values are well stable, 

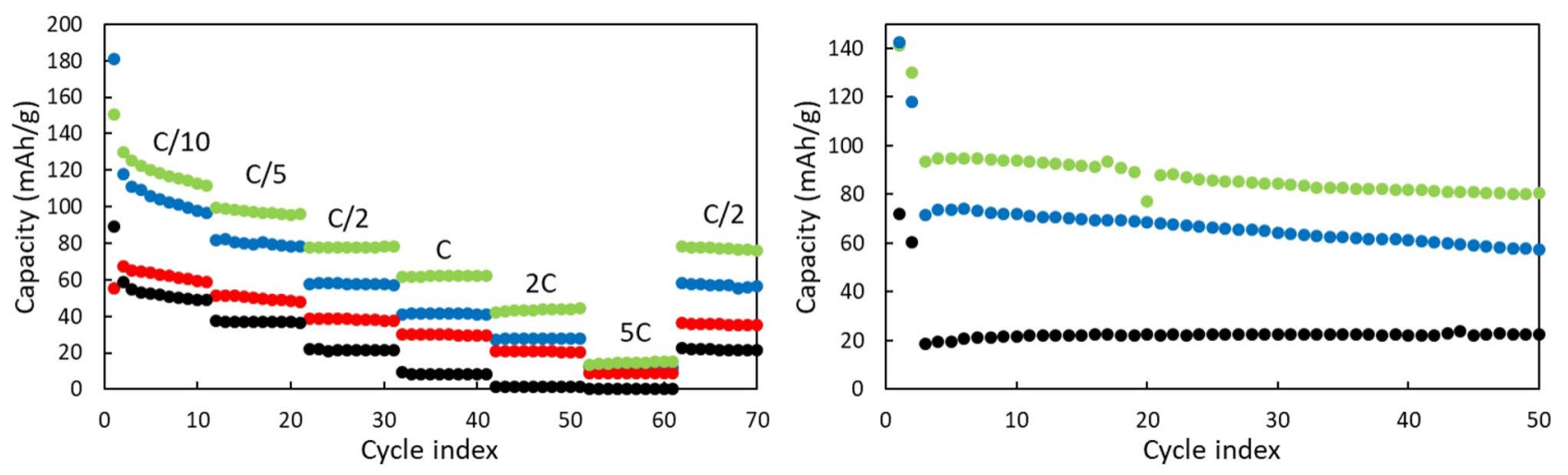

Fig. 7 Discharge capacity values at different C-rates (NMFO, black; NMFO-Al, red; NMFO-Si, blue and NMFO-Cu, green) and long cycling (50 cycles) at C/2 for NMFO-Cu (green) and NMFO-Si (blue), compared with NMFO (black)

only a slight decrease can be evidenced in both cases: a capacity retention of about $86 \%$ and $80 \%$ can be calculated. The comparison with NMFO shows the positive effect of the addition of other cations on the performance.

The Silicon substitution was never reported for this kind of materials: we suppose that its influence can be mainly expressed on the bonds strength. The copper instead can help to suppress the Jahn-Teller effect of $\mathrm{Mn}^{3+}$ and provide its contribution to the capacity values, because $\mathrm{Cu}^{2+}$ / $\mathrm{Cu}^{3+}$ redox couple is electrochemically active. In addition, the improvement of the air stability of the material, as determined by XRPD, is a very tempting result.

Almost all the samples show quite large irreversibility in the first couple of cycles. The origin of such a problem can be spotted from Fig. 8 . The 1 st charge greatly differs from the others, likely because of the phase evolution during cycling: the original mixture of phases ( $\mathrm{P} 3$ and $\mathrm{P}^{\prime} 3$ for most samples, occasionally with some $\mathrm{O} 3$ or $\mathrm{P} 2$ amount) converts into low $\mathrm{Na}$ /f.u. phases (up to $\mathrm{Mn}_{0.5} \mathrm{Fe}_{0.5} \mathrm{O}_{2}$ and the correlated doped samples, theoretically) and then back to a higher sodium content one during discharge. Due to the electrochemical nature of the sodiation, which is well-known for affecting the formation of metastable phases that cannot be obtained outside electrochemical cells, a different mixture of phases is the starting point for the 2 nd cycle. It can be inferred that the electrochemically re-sodiated phases are less electrochemically active than the starting active material, for which larger capacities are always obtained.

\section{Discussion}

$\mathrm{NMO}$ is a well-known material in NIBs with encouraging electrochemical properties, but with some drawbacks, in particular the Jahn-Teller distortion accompanied by the reduction of $\mathrm{Mn}^{4+}$ to $\mathrm{Mn}^{3+}$ inducing the failure of
$\mathrm{Na}_{0.44} \mathrm{MnO}_{2}$ lattice upon $\mathrm{Na}^{+}$intercalation, resulting in unsatisfactory cycling performance $[9,22]$. The doping is considered as a good way to mitigate this problem. In our paper, the choice to introduce Fe ions into NMO lattice is due to the will to improve the cell operational voltage, up to at least $3.56 \mathrm{~V}$ or higher. This introduction, however, produced the structure change, from S-tunnel type to layered one. The original NMO structure, to mainly preserve its high air stability, can be maintained by the use of proper dopant, such as Ti $[1,26]$. In our case instead, we were interested in stabilizing layered phases, and all the chosen dopant ( $\mathrm{Al}, \mathrm{Si}$ and $\mathrm{Cu}$ ) provided samples that offer interesting hints for discussion. First, all of them are easily substituted into NMFO lattice, inducing slightly different phases stabilization. NMFO-AI and NMFO-Si have two opposite behaviour: for the first one the preferred phase is P'3, while for Si doping it is the "regular" P3. The differences between these two layered polymorphs reside in the different crystal symmetry, monoclinic for the $P^{\prime} 3$ and hexagonal for $\mathrm{P} 3$ and, for this reason, $\mathrm{P}^{\prime} 3$ is referred in the literature as a distorted form of P3 [27]. To explain the preference towards one of these polymorphs, we can perform some hypotheses based on charge balance into layered materials. In NMFO we can expect the presence of $\mathrm{Mn}^{4+}$ and $\mathrm{Fe}^{3+}$ in equal amount. When a trivalent cation $\left(\mathrm{Al}^{3+}\right)$ is introduced on both $\mathrm{Mn}$ and Fe sites, there is the need to increase the amount of $4+$ cations (such as $\mathrm{Fe}^{4+}$ ) or to produce oxygen vacancies. In both cases, we can expect some distortion of the octahedra, due to the Jahn-Teller $\mathrm{Fe}^{4+}$ ions or to the lack of oxygen. This could be the reason of the lowering of the phase symmetry. When instead a tetravalent cation $\left(\mathrm{Si}^{4+}\right)$ is used as a substituent, it can induce the reduction of $\mathrm{Mn}$ to $\mathrm{Mn}^{2+}$, well stable in regular octahedral sites, so allowing to maintain the "regular" P3 lattice. The reduction of $\mathrm{Fe}^{3+}$ to $\mathrm{Fe}^{2+}$ seems less likely. For $\mathrm{Cu}$ doping $\left(\mathrm{Cu}^{2+}\right)$ a hybrid situation is detected: both P3 and P'3 polymorphs are formed in significant amount, 

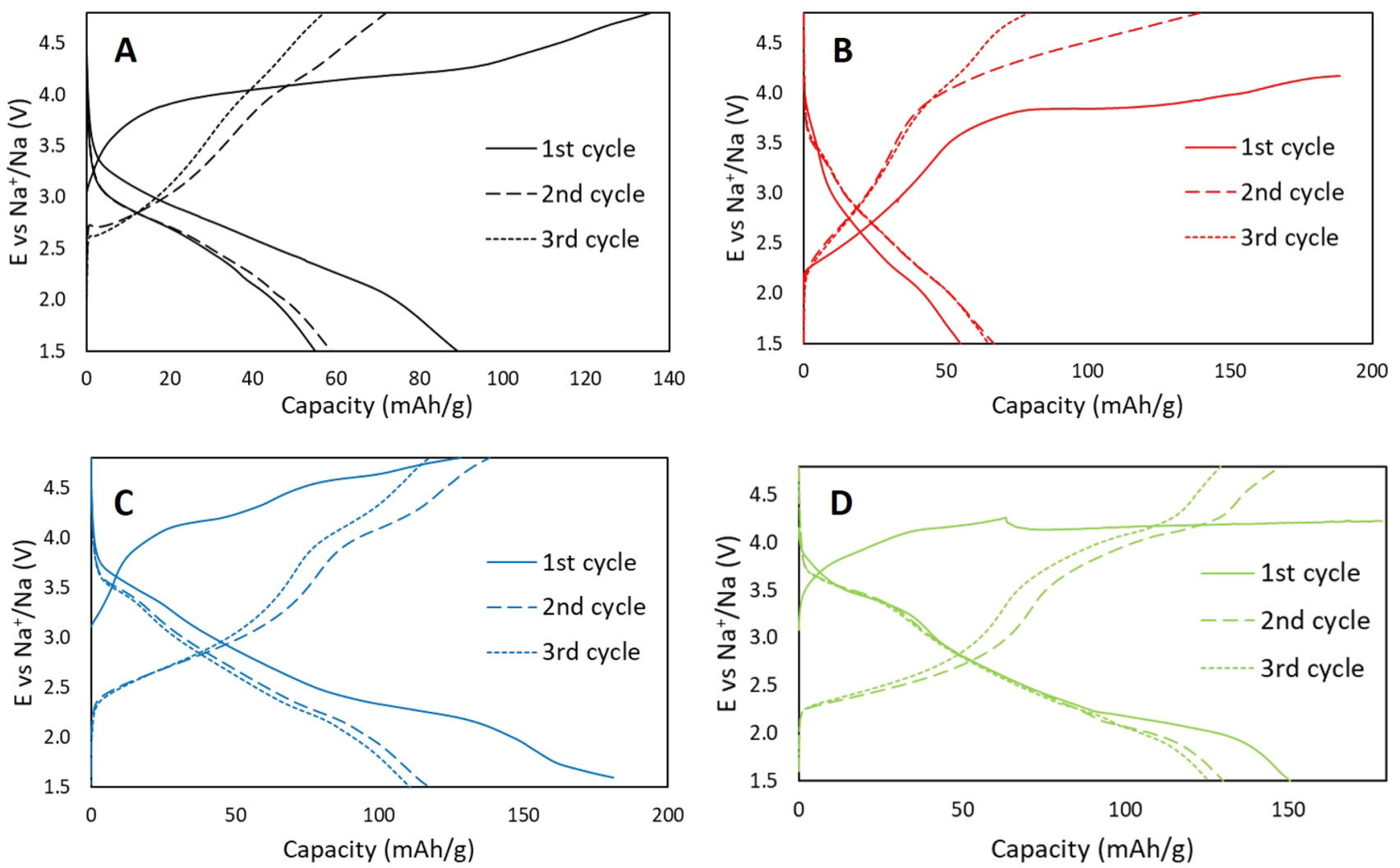

Fig. 8 Voltage profiles of the first 3 cycles, for NMFO (A), NMFO-AI (B), NMFO-Si (C) and NMFO-Cu (D)

even if with the preference towards the monoclinic phase. Copper inhibits the Mn reduction, favouring instead $\mathrm{Fe}^{4+}$ or oxygen vacancies formation. So, we can expect the $\mathrm{P}^{\prime} 3$ preferred stabilization, but the presence of $\mathrm{Na}$ inhomogeneity in the sample stabilizes also the $\mathrm{P} 3$ phase. It was demonstrated from EDS measurements (Fig. 4), that two phases with slightly different chemical compositions of $\mathrm{Na}$ and $\mathrm{Cu}$ are stabilized, probably corresponding to $\mathrm{P} 3$ and $\mathrm{P}^{\prime} 3$ polymorphs. The NMFO-Cu sample is the most promising, for what concern air stability and electrochemical performances. The first aspect, even if not mandatory for electrode materials assembled in the cell under inert conditions, can be useful for handling the material during the synthesis steps and the slurries preparation. The high structural stability in air does not seem to be related to the polymorph type (which are very similar in all the prepared samples), but could be related instead to the synthesis route (solid state for the most air-stable samples).

For what concerns the electrochemical behaviour of NMFO-Cu, both the rate capability test and the long-term cycling show satisfactory results: at $1 \mathrm{C}, 60 \mathrm{mAh} / \mathrm{g}$ of capacity can be obtained, while for the prolonged cycling at $\mathrm{C} / 2$, a capacity retention of about $86 \%$ is determined after 50 cycles.

\section{Conclusion}

In the present paper, we demonstrated that the use of substituents in a classical cathode material for NIBs allowed to stabilize mixtures of layered polymorphs. Si and $\mathrm{Cu}$ substitution into $\mathrm{Na}_{0.44} \mathrm{Mn}_{0.5} \mathrm{Fe}_{0.5} \mathrm{O}_{2}$ seems the most promising, this last one producing higher capacity values and improved air stability. The copper substitution, in particular, can be considered an advisable method to suppress surface side effects and improve the electrochemical properties of manganese-rich materials.

Acknowledgements We thank the RSE (Ricerca per il Sistema Elettrico) for the fruitful collaboration.

Authors contribution $\mathrm{MN}$ : Methodology, Investigation; DS Formal analysis, Writing Original Draft; IQ: Visualization; PG, BA, SC: Investigation; MB: Conceptualization, Supervision, Writing Original Draft.

Funding Open access funding provided by Università degli Studi di Pavia within the CRUI-CARE Agreement. This research did not receive any specific grant from funding agencies in the public, commercial, or not-for-profit sectors. 


\section{Compliance with ethical standards}

Conflict of interest On behalf of all authors, the corresponding author states that there is no conflict of interest.

Open Access This article is licensed under a Creative Commons Attribution 4.0 International License, which permits use, sharing, adaptation, distribution and reproduction in any medium or format, as long as you give appropriate credit to the original author(s) and the source, provide a link to the Creative Commons licence, and indicate if changes were made. The images or other third party material in this article are included in the article's Creative Commons licence, unless indicated otherwise in a credit line to the material. If material is not included in the article's Creative Commons licence and your intended use is not permitted by statutory regulation or exceeds the permitted use, you will need to obtain permission directly from the copyright holder. To view a copy of this licence, visit http://creativecommons .org/licenses/by/4.0/.

\section{References}

1. Kubota K, Kumakura S, Yoda Y, Kuroki K, Komaba S (2018) Electrochemistry and solid-state chemistry of $\mathrm{NaMeO}_{2}(\mathrm{Me}=3 \mathrm{~d}$ transition metals). Adv Energy Mater 8:1703415

2. Kim H, Kim H, Ding Z, Lee MH, Lim K, Yoon G, Kang K (2016) Recent progress in electrode materials for sodium-ion batteries. Adv Energy Mater 6:1600943

3. Deng Y-P, Wu Z-G, Liang R, Jiang Y, Luo D, Yu A, Chen Z (2019) Layer-based heterostructured cathodes for lithium-ion and sodium-ion batteries. Adv Funct Mater 29:1808522

4. Chen M, Liu Q, Wang S-W, Wang E, Guo X, Chou S-L (2019) Highabundance and low-cost metal-based cathode materials for sodium-ion batteries: problems, progress, and key technologies. Adv Energy Mater 9:1803609

5. Wang S, Sun C, Wang N, Zhang Q (2019) Ni- and/or Mn-based layered transition metal oxides as cathode materials for sodium ion batteries: status, challenges and countermeasures. J Mater Chem A 7:10138-10158

6. Sun Y, Guo S, Zhou H (2019) Adverse effects of interlayer-gliding in layered transition-metal oxides on electrochemical sodiumion storage. Energy Environ Sci 12:825-840

7. Parant JP, Olazcuaga $R$, Devalette $M$, Fouassier $C$, Hagenmuller $P(1971)$ Sur quelques nouvelles phases de formule $\mathrm{Na}_{x} \mathrm{MnO}_{2}$ $(x<1)$. J Solid State Chem 3:1-11

8. Zhang D, Shi W-J, Yan Y-W, Xu S-D, Chen L, Wang X-M, Liu S-B (2017) Fast and scalable synthesis of durable $\mathrm{Na}_{0.44} \mathrm{MnO}_{2}$ cathode material via an oxalate precursor method for Na-ion batteries. Electrochim Acta 258:1035-1043

9. Liu Y, Liu X, Bu F, Zhao X, Wang L, Shen Q, Zhang J, Zhang N, Jiao L, Fan L-Z (2019) Boosting fast and durable sodium-ion storage by tailoring well-shaped $\mathrm{Na}_{0.44} \mathrm{MnO}_{2}$ nanowires cathode. Electrochim Acta 313:122-130

10. Delmas C, Fouassier C, Hagenmuller P (1980) Structural classification and properties of the layered oxides. Physica 99B:81-85

11. Shao Y, Zhou Y-T, Deng M-M, Tang Z-F, Liao J-Y, Bouwmeester $\mathrm{HJM}$, Chen C-H (2019) Performance of $\mathrm{Na}_{0.44} \mathrm{Mn}_{1-x} \mathrm{M}_{\mathrm{x}} \mathrm{O}_{2}(\mathrm{M}=\mathrm{Ni}$, $\mathrm{Mg} ; 0 \leq x \leq 0.44)$ as a cathode for rechargeable sodium ion batteries. J Solid State Electrochem 23:2979-2988

12. Lilu L, Xingguo Q, Yongsheng H, Liquan C, Xuejie H (2017) Novel Cu based oxides with tunnel structure as cathode for sodiumion batteries. Acta Chim Sinica 75:218-224
13. Mortemard de Boisse B, Carlier D, Guignard M, Bourgeois L, Delmas C (2014) $\mathrm{P} 2-\mathrm{Na}_{x} \mathrm{Mn}_{1 / 2} \mathrm{Fe}_{1 / 2} \mathrm{O}_{2}$ phase used as positive electrode in na batteries: structural changes induced by the electrochemical (de)intercalation process. Inorg Chem 53:11197-11205

14. Yabuuchi N, Kajiyama M, Iwatate J, Nishikawa H, Hitomi S, Okuyama R, Usui R, Yamada Y, Komaba S (2012) P2-type $\mathrm{Na}_{\mathrm{x}}\left[\mathrm{Fe}_{1 / 2} \mathrm{Mn}_{1 / 2}\right] \mathrm{O}_{2}$ made from earth-abundant elements for rechargeable Na batteries. Nat Mater 11:512-517

15. Yoncheva M, Stoyanova R, Zhecheva E, Kuzmanova E, SendovaVassileva M, Nihtianova D, Carlier D, Guignard M, Delmas C (2012) Structure and reversible lithium intercalation in a new P'3-phase: Na2/3Mn1-yFeyO2 $(y=0,1 / 3,2 / 3)$. J Mater Chem 22:23418-23427

16. Chen T, Liu W, Zhuo Y, Hu H, Guo J, Liu Y, Yan J, Liu K (2019) Copper surface doping to improve the structure and surface properties of manganese-rich cathode materials for sodium ion batteries. Mater Chem Front 3:2374-2379

17. Kong W, Gao R, Li Q, Yang W, Yang J, Sun L, Liu X (2019) Simultaneously tuning cationic and anionic redox in a $\mathrm{P} 2-\mathrm{Na} 0.67 \mathrm{Mn} 0.75 \mathrm{Ni} 0.25 \mathrm{O} 2$ cathode material through synergic $\mathrm{Cu} / \mathrm{Mg}$ co-doping. J Mater Chem A 7:9099-9109

18. Bruker AXS (2005) TOPAS V3.0: General profile and structural analysis software for powder diffraction data. User Manual Bruker AXS, Karlsruhe

19. Khan MA, Han D, Lee G, Kim Y-IL, Kang Y-M (2019) P2/O3 phaseintegrated $\mathrm{Na} 0.7 \mathrm{MnO} 2$ cathode materials for sodium-ion rechargeable batteries. J Alloys Compound 771:987-993

20. Xiao $Y$, Wang $P-F$, Yin Y-X, Zhu Y-F, Yang X, Zhang X-D, Wang Y, Guo X-D, Zhong B-H, Guo Y-G (2018) A layered-tunnel intergrowth structure for high-performance sodium-ion oxide cathode. Adv Energy Mater 8:1800492

21. Li Z-Y, Zhang J, Gao R, Zhang H, Hu Z, Liu X (2016) Unveiling the role of co in improving the high-rate capability and cycling performance of layered $\mathrm{Na} 0.7 \mathrm{Mn} 0.7 \mathrm{NiO} 0.3-\mathrm{xCoxO} 2$ cathode materials for sodium-ion batteries. ACS Appl Mater Interfaces 8:15439-15448

22. Zhang Y, Zhang R, Huang Y (2019) Air-Stable NaxTMO2 Cathodes for Sodium Storage. Front Chem 7:335

23. Chen C, Han B, Lin G, Huang Q, Zhao S, Zhang D, Ma C, Ivey DG, Wei W (2018) Electrochemical property-structure correlation for Ni-based layered Na-lon cathodes. ACS Appl Mater Interfaces 10:28719-28725

24. Sun Y, Guo S, Zhou H (2019) Exploration of Advanced electrode materials for rechargeable sodium-ion batteries. Adv Energy Mater 9:1800212

25. Zhang Y, Liu L, Jamil S, Xie J, Liu W, Xia J, Nie S, Wang X (2019) Al2O3 coated $\mathrm{Na} 0.44 \mathrm{MnO} 2$ as high-voltage cathode for sodium ion batteries. Appl Surf Sci 494:1156-1165

26. Xu S, Wang $Y$, Ben L, Lyu Y, Song N, Yang Z, Li Y, Mu L, Yang H-T, Gu L, Hu Y-S, Li H, Cheng Z-H, Chen L, Huang X (2015) Fe-based tunnel-type $\mathrm{Na} 0.61$ [Mn 0.27 Fe 0.34 Ti 0.39] 2 designed by a new strategy as a cathode material for sodium-ion batteries. Adv Energy Mater 5:1501156

27. Komaba S, Nakayama T, Ogata A, Shimizu T, Takei C, Takada S, Hokura A, Nakai I (2009) Electrochemically reversible sodium

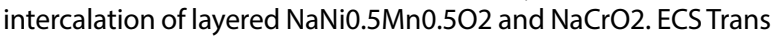
16:43-55

Publisher's Note Springer Nature remains neutral with regard to jurisdictional claims in published maps and institutional affiliations. 